\title{
Strength Difference between Clam-Shell and Long-Reach Excavator Constructed Cement-Bentonite Self-Hardening Slurry Walls
}

\author{
Paul J. Axtell ${ }^{1}$, P.E., Timothy D. Stark ${ }^{2}$, Ph.D., P.E., and John C. Dillon ${ }^{3}$, P.E.
}

\author{
${ }^{1}$ Dan Brown and Associates, paxtell@danbrownandassociates.com \\ ${ }^{2}$ University of Illinois, tstark@ uiuc.edu \\ ${ }^{3}$ US Army Corps of Engineers, Kansas City District, john.c.dillon@usace.army.mil
}

\begin{abstract}
Cement-bentonite (c-b) self-hardening slurry walls are being constructed as a seismic retrofit to stabilize the downstream slope of Tuttle Creek Dam in Manhattan, Kansas. A full-scale test program was conducted to evaluate various slurry mixes along with two construction techniques capable of creating the required c-b transverse shear walls. The two methods tested were a crane-operated mechanical clam-shell excavator (CS) and a long-reach track-hoe (LR). The results of unconfined compression tests on hardened c-b samples constructed by CS and LR techniques were measured and the comparison revealed different unconfined compressive strengths (UCS). This paper presents UCS for both construction techniques and sample type, i.e., cored and wet-grab samples. The cause(s) of the differences in UCS and the impact on the remedial measures are discussed.
\end{abstract}

\section{INTRODUCTION}

Tuttle Creek Dam, located on the Big Blue River in the Kansas River Basin, is part of a system that provides a comprehensive plan for flood control and other functions in the Missouri River Basin. The dam was designed and constructed by the US Army Corps of Engineers, Kansas City District. It is located about $10 \mathrm{~km}$ north of the city of Manhattan in eastern Kansas. The embankment is 2,300 $\mathrm{m}$ long and about $43 \mathrm{~m}$ high. The crest width is $15.2 \mathrm{~m}$ and the base width varies from about 430 to $490 \mathrm{~m}$. The top of the dam is at elevation $353.3 \mathrm{~m}$ while the original ground surface varies in elevation from about 310 to $313 \mathrm{~m}$ across the valley. Tuttle Creek Dam is a rolled earthfill dam; details of the fill zones and construction of the dam can be found in Lane and Fehrman (1960).

The main seismic source zones are the Nemaha Ridge uplift zone and the Humboldt Fault zone. The maximum credible earthquake (MCE) is a magnitude 6.6 event at 20 $\mathrm{km}$ with a return period of about 3000 years. The peak horizontal ground acceleration, PHGA, of the MCE is $0.30 \mathrm{~g}$ mean and $0.56 \mathrm{~g}$ mean plus one standard deviation. The threshold liquefaction event is a magnitude 5.7 with a return period of 
about 1700 years. The Kansas City District found that rehabilitation of the liquefiable foundation sands is required to prevent an uncontrolled release of the reservoir during or after the design ground motion.

As part of the required seismic rehabilitation, transverse shear walls are being constructed through the embankment and foundation soils near the downstream toe of the dam. The walls are oriented perpendicular to the crest of the dam to resist deformations induced by slope instability following the design seismic event. Large deformations at the downstream toe are not acceptable because of the presence of a fragile pressure relief well system. This relief well system provides vital underseepage pressure relief during operation of the reservoir.

The test program was considered both a test and production treatment covering approximately 10 percent of the required stabilization of the downstream stabilization project. Replacement walls were added as required between walls after initial construction to assure the designed strength was achieved. The construction contractor (Treviicos South) worked closely with the Corps to identify the most effective technologies, materials, and configurations to be used in the test program and subsequent design and full production at part of the Construction Manager at Risk contract.

\section{CONSTRUCTION DETAILS}

Thirty-eight test walls were constructed in this test program. Twenty-two walls were constructed using the CS while 16 were constructed with the LR. Four of the CS walls included a higher slag cement component than used in the LR walls, and therefore are not included in this comparison, leaving only $18 \mathrm{CS}$ walls to include in the dataset. Tremie-placed plastic concrete was attempted on two walls, but was abandoned after trench stability problems were observed during construction. Four self-hardening slurry mixes were trialed with each construction method. The four cement-to-water ratios used were $0.3,0.4,0.45$, and 0.5 with 5 percent bentonite, as shown in Table 1, along with the number of walls built with each method utilizing a respective mix.

The walls were excavated and simultaneously backfilled with self-hardening c-b slurry supplied by an on-site batch plant. A Liebherr HS855DH crane was used for the CS walls while a Koehring 1466 excavator was used for the LR walls. The CS walls were predominantly constructed by excavating three $4 \mathrm{~m}$ long primary bites/excavations, followed by two $1 \mathrm{~m}$ wide secondary bites/excavations. Necessarily, the LR walls were built in a single phase. Walls constructed with the CS were generally completed in about 1.5 days, while walls constructed with the LR took slightly less than a day. Neither method included a 24-hour operation.

The water used in the c-b mix was obtained from a well screened in the foundation sand just beyond the downstream toe of the dam. The cement used was MaxCem ${ }^{\circledR}$ which was obtained from Lafarge, and was composed of 50 percent Portland cement and 50 percent ground granulated blast furnace slag cement. The bentonite used was Wyo-Ben Hydrogel ${ }^{\circ}$. A dispersing agent admixture Lamsperse-HS, available through Lamberti, was also used in the mix. The bentonite was mixed with water in a high speed mixer and allowed to hydrate under continuous circulation for 8 to 12 
hours. The cement was then mixed with the bentonite slurry in a high speed mixer. All mixes include a 5 percent bentonite component.

The walls are $13.7 \mathrm{~m}$ long, and $21 \mathrm{~m}$ deep with a $3 \mathrm{~m}$ clear space between them. The CS walls are $122 \mathrm{~cm}$ wide while the LR walls are $91 \mathrm{~cm}$ wide. The extra CS width was required to provide extra mass as a $91 \mathrm{~cm}$ wide clamshell was not large enough to efficiently excavate to the specified depths due to the relatively high density of the fluid slurry. The clear space between the walls is required to allow continued through seepage in the pervious drain downstream of the core and underseepage in the coarse-grained foundation soils. Restricting either of these seepage paths would result in unacceptable build-up of pore pressures and possibly slope instability.

Table 1. Various construction methods and corresponding mixes.

\begin{tabular}{|c|c|c|c|c|}
\hline $\begin{array}{l}\text { Number of } \\
\text { CS Walls }\end{array}$ & $\begin{array}{l}\text { Number of } \\
\text { LR Walls }\end{array}$ & $\begin{array}{c}\text { Cement-to- } \\
\text { Water Ratio }\end{array}$ & $\begin{array}{c}\text { Lamsperse-HS } \\
(\%)\end{array}$ & $\begin{array}{l}\text { Theoretical Unit } \\
\text { Weight }\left(\mathrm{kN} / \mathrm{m}^{3}\right)\end{array}$ \\
\hline 4 & 4 & 0.3 & 0.3 to 0.6 & 11.8 \\
\hline 7 & 4 & 0.4 & 0.4 to 0.8 & 12.3 \\
\hline 4 & 4 & 0.45 & 0.45 to 0.9 & 12.5 \\
\hline 3 & 4 & 0.5 & 0.5 to 1.0 & 12.7 \\
\hline
\end{tabular}

\section{SOIL PROFILE}

A working platform was constructed on the downstream slope of the dam to facilitate construction of the walls. The platform was constructed by: 1) removing the existing fill to expose the pervious drain fill; 2) importing and placing sand (SP); and 3) placing approximately $60 \mathrm{~cm}$ of road sub-base for a working surface. The only portion of the embankment the walls are in contact with is the pervious drain downstream of the core, which lies above the natural cohesive blanket (ML and CL). The pervious drain fill is composed of dense dredged SP soil, and is approximately $4.6 \mathrm{~m}$ thick.

The soils in the alluvial foundation of the dam consist of 2.4 to $8.2 \mathrm{~m}$ of silt and clay underlain by sand, silty sand, and gravely sand to a depth of 12.2 to $24.4 \mathrm{~m}$. The silt and clay form a natural cohesive soil blanket over the more permeable sands. This natural cohesive blanket is an important component of the seepage control system for the dam, as are the pressure relief wells at the downstream toe. The sand deposits vary in thickness from about 7.6 to $18.3 \mathrm{~m}$ and can be separated into two distinct zones. The upper zone consists of a 4.6 to $6.1 \mathrm{~m}$ thick loose fine to medium sand (SM, SP, and SW) and the lower zone consists of a 7.6 to $9.1 \mathrm{~m}$ thick dense coarse to gravelly sand that increases in grain-size with depth (SP, SW, GP, GW). Due to the alluvial nature of the foundation deposit, multiple lenses of cohesive soil exist within the coarse-grained layers. The upper sand zone was determined to be potentially liquefiable during the design ground motion. The bedrock consists of alternating layers of shale and limestone (Permian age); however, the walls do not penetrate bedrock. 


\section{SAMPLING AND TESTING}

Sampling and testing was performed at the on-site batch plant, on the fluid c-b slurry in the excavations via wet-grab samples, and on the hardened c-b slurry via core drilling. Wet-grab sampling was conducted on each wall at various depths. Wet-grab samples were cast in $7.6-\mathrm{cm}$ by $15.2-\mathrm{cm}$ cylinders and stored in a 100 percent humidity curing room until UCS testing was performed. Eventually, all samples (plant, wet-grab, and core) were stored submerged in water after it became apparent the samples were degrading with time in a 100 percent humidity curing room. This degradation was not apparent for samples cured for 28 days, but was visually noticeable for the 60 day samples and older.

Coring was conducted on the majority of the walls. Initially, coring was conducted with the Geobore system (double-barrel wireline) producing $10 \mathrm{~cm}$ diameter samples. Due to a significant strength discrepancy between the wet-grab and core sample strength, the coring operation was altered to a split-barrel coring device in an effort to reduce sample disturbance and micro-fracturing.

Based on an independent laboratory investigation of the proposed mixes, and verified by full-scale field measurements, relatively minor strength increases can be expected beyond 90 days for these materials. The ratio of slag cement to Portland cement, the type of Portland cement, and the amount of bentonite included in the mix likely control the rate of strength gain.

The changes in sample storage and coring operation requires two independent data sets be developed, one for each set of techniques (the changes in storage and coring were instituted at the same time). Accordingly, the data reported herein was sampled and stored in the following manner:

1. 28-day UCS tests (Figures 1 through 4)

a. Coring with the Geobore system conducted between 14- to 28-days after panel construction.

b. Wet-grab samples cured in 100 percent humidity room for 28 days.

2. Long-term UCS tests (Figure 5)

a. Coring with split-barrel device a minimum of 120 days after panel construction.

b. Strength testing performed immediately after coring or within two weeks after coring (submerged storage in the interim).

\section{INTERPRETATION OF TEST RESULTS}

The UCS results indicated that the strength varies with respect to several variables in the construction and testing process, resulting in a complex dataset. The influencing factors, among others, appear to be: 1) depth, 2) construction method, 3) sample type, 4) cement/water ratio, and potentially 5) slag content.

The measured strength of both wet-grab and core samples with depth for the CS and LR construction methods are shown in Figures 1 through 4 for the four c/w ratios of $0.5,0.45,0.4$, and 0.3 , respectively. From these figures, it appears the core sample strength varies more with depth than the wet-grab sample strengths. The variation 
with depth of the core strengths is likely a result of various material types being excavated in addition to the duration which the soil particles remain in suspension within the fluid slurry. The wet-grab strengths do not appear to be as depthdependent, suggesting there is an effect of continued soil particle settlement within the fluid slurry, or perhaps the confining stress during curing (higher in the fluid walls for the core samples) alters the strength.

Another complicating factor is the construction method which appears to influence the measured strength of the core samples, but not the wet-grab samples. While much scatter exists in the data, it seems evident that the core strength for the LR samples is greater than that of the CS core samples. The CS and LR construction methods likely leave different amounts of suspended soil in the fluid slurry, the results of which are probably more likely to affect core strength than wet-grab strength.

The differences between wet-grab and core strength is more pronounced at higher $\mathrm{c} / \mathrm{w}$ ratios. The results shown in Figure 4 for the mix with $\mathrm{c} / \mathrm{w}$ ratio of 0.3 indicate very similar strengths between the two sample types, as opposed to the 0.5 mix shown in Figure 1. This suggests the density of the fluid slurry has an effect not only on the settlement of suspended soil particles, but also cement particles.

Further evaluation of density and sand content measurements on wet-grab samples, as well as density measurement of core samples could likely yield insight into the peculiar differences in core and wet-grab strength at various $\mathrm{c} / \mathrm{w}$ ratios. While careful coring was conducted, as well as using multiple coring operations, the potential of micro-fracture of samples during coring must also be considered. The samples tested herein reached peak strength around one percent axial strain, indicating a relatively brittle material, as expected. The post-peak or ultimate strength measured on core samples via isotropic-consolidated, undrained triaxial tests with pore-pressure measurements was taken into consideration during the design of these walls for the seismic retrofit because some cracking of the walls is expected during the design ground motions.

To quantify the observed strength difference between LR and CS core samples, the average long-term strengths at various c/w ratios are shown in Figure 5. The definition of "long-term" refers to samples that were cored at least 90 days after construction of the walls. Necessarily, the average includes samples at various depths. As noted earlier, the strength of cored samples does vary with depth. However, the average trends suggest the strength of LR constructed walls exceeds that of CS walls by 20 to 52 percent at various c/w ratios.

Although a good data set was not developed for higher slag contents, it should be noted a 75 percent slag mix (as opposed to the 50 percent slag mix) was used on four CS walls (two with a cement-to-water ratio of 0.3 and two with a cement-to-water ratio of 0.4 ). Their average long-term UCS were 1.65 and $2.46 \mathrm{MPa}$ for the 0.3 and 0.4 mixes, respectively; a significant increase than those values shown in Figure 5 for 50 percent slag mixtures. 


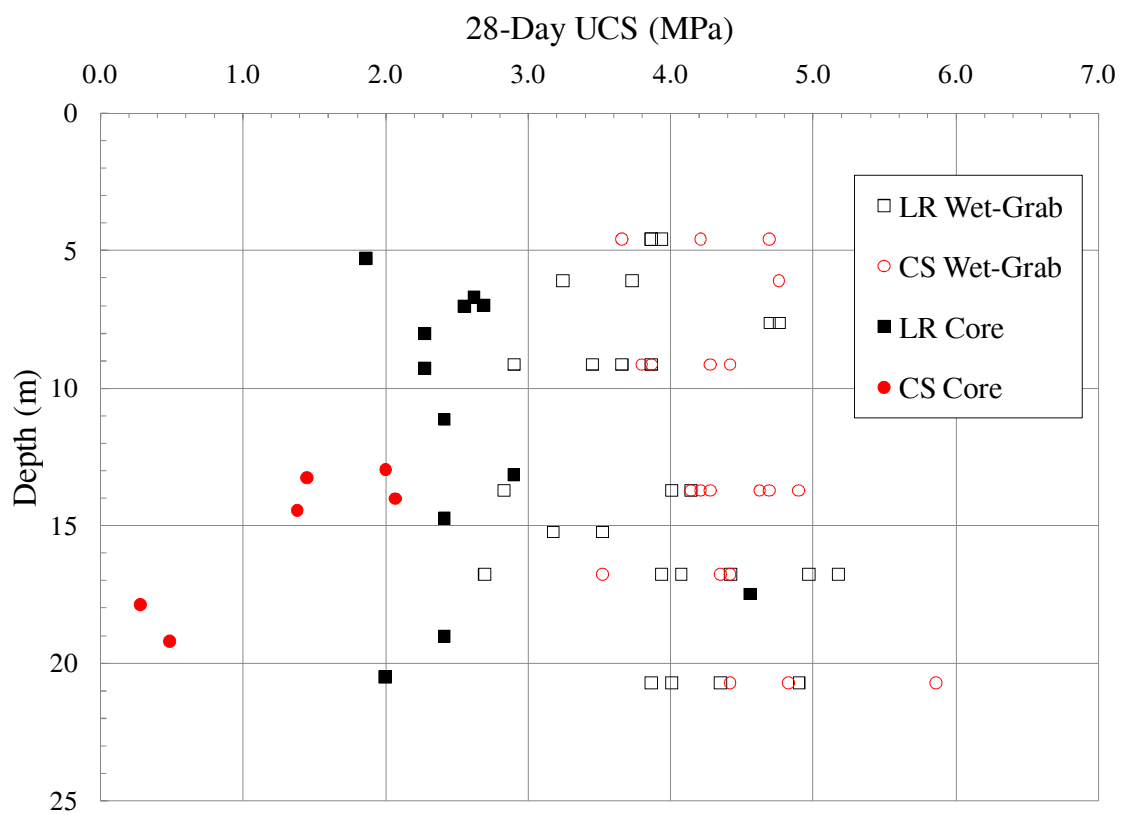

Figure 1. UCS for cement-to-water ratio of 0.5 .

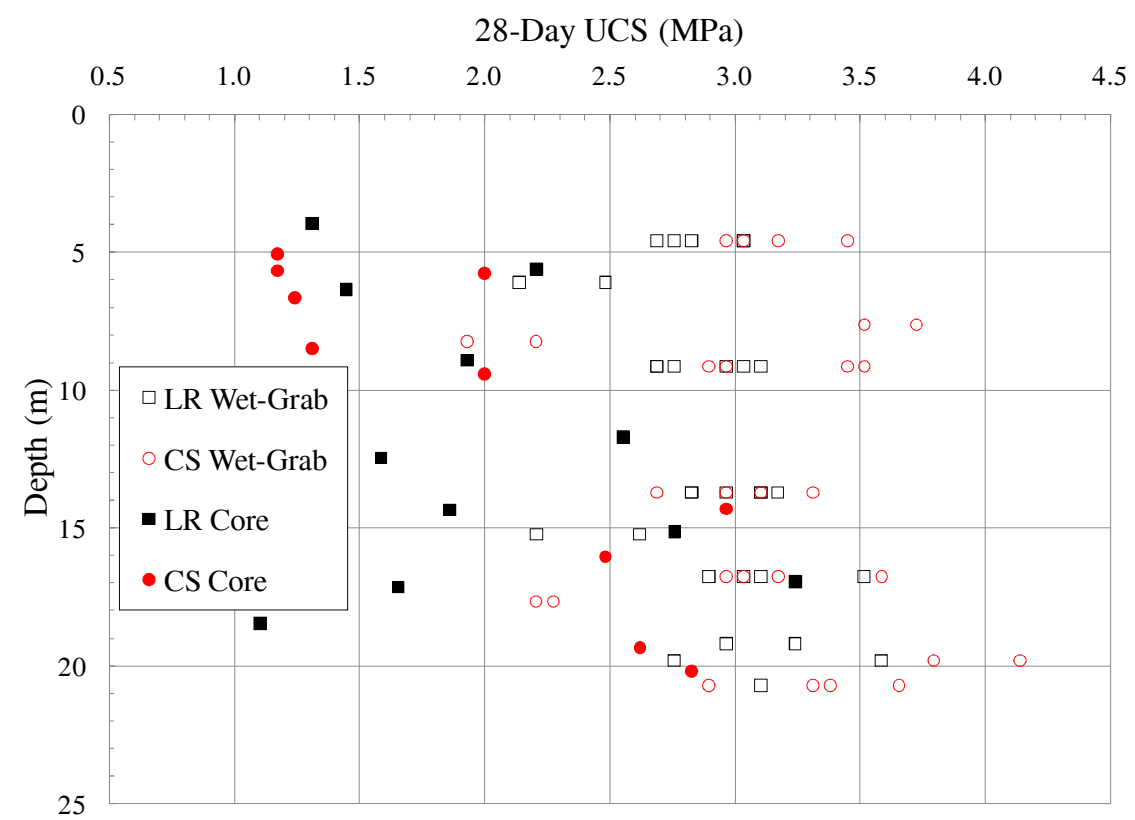

Figure 2. UCS for cement-to-water ratio of 0.45 . 


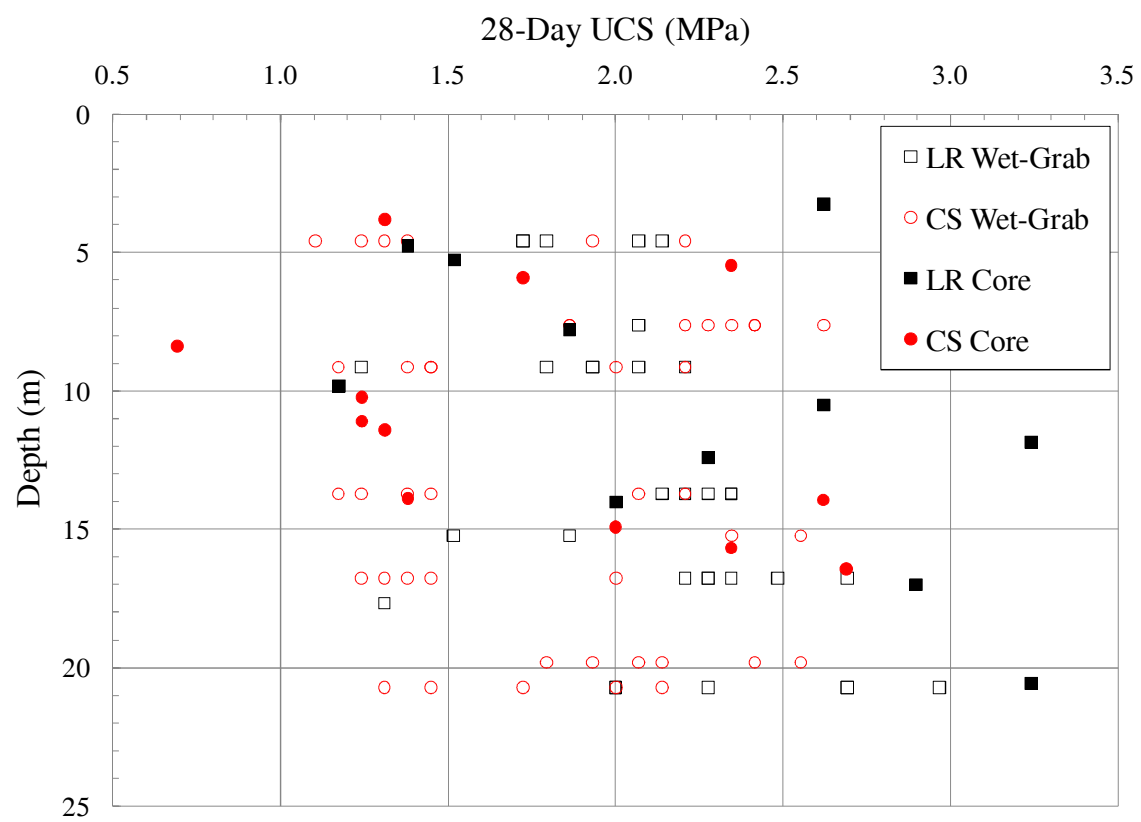

Figure 3. UCS for cement-to-water ratio of 0.4 .

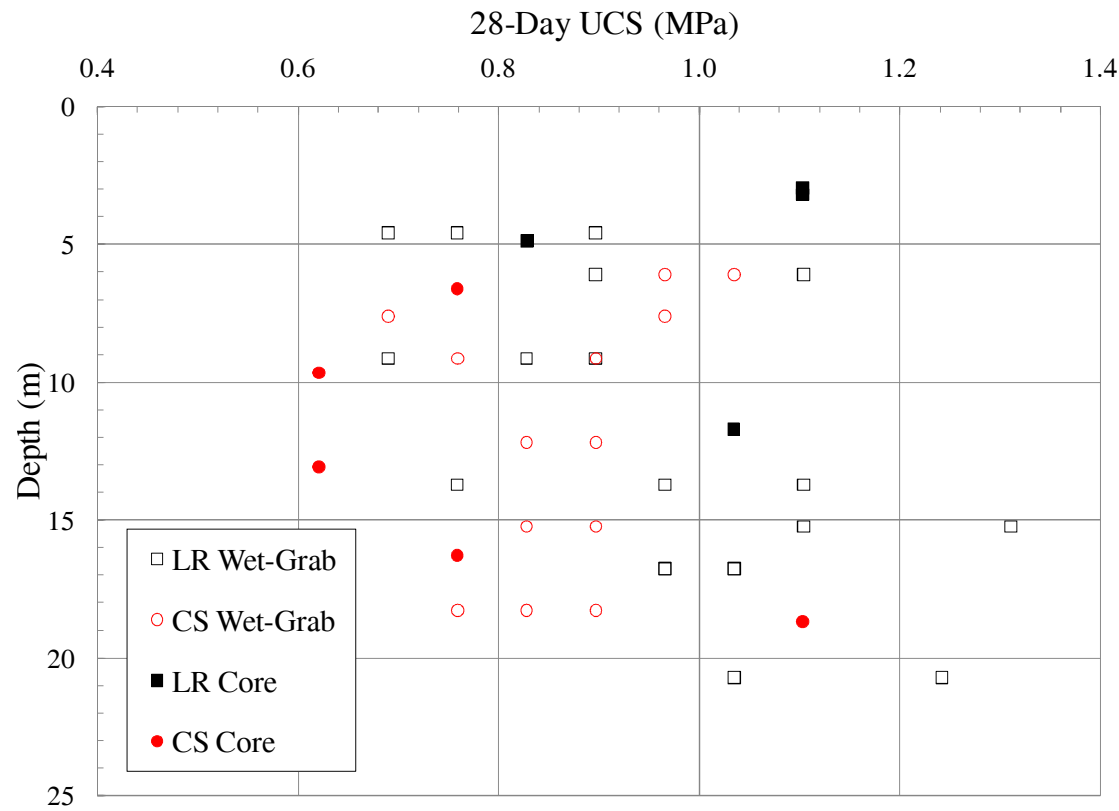

Figure 4. UCS for cement-to-water ratio of 0.3 . 


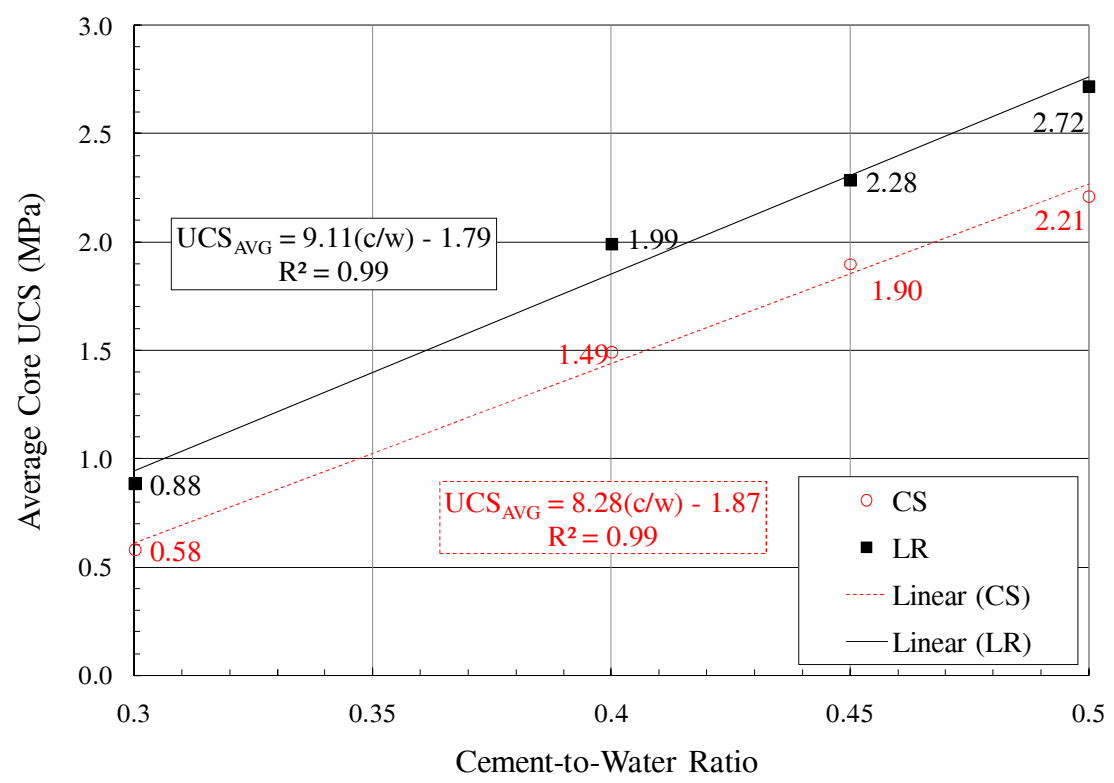

Figure 5. Average long-term UCS of core samples.

\section{CONCLUSIONS}

Cement-bentonite (c-b) self-hardening slurry walls are being constructed as a seismic retrofit of the downstream slope of Tuttle Creek Dam. A full-scale test was conducted to evaluate LR and CS construction techniques. The results of UCS tests on hardened c-b samples constructed by CS and LR techniques revealed different UCS for these construction methods. On average, walls constructed with the LR method appear to yield stronger core samples than those constructed with the CS method. The sample type, i.e., cored versus wet-grab samples, yield significantly different strengths at high c/w ratios, and essentially no difference at low c/w ratios.

\section{ACKNOWLEDGMENTS}

The contents of this paper are the authors' and do not necessarily reflect those of the represented entities. The authors acknowledge the support provided by the U.S. Army Corps of Engineers - Kansas City District, Joe Topi, Francke Walberg, Bill Empson, and the expertise of the contractor, Treviicos South.

\section{REFERENCES}

Lane, K.S., and Fehrman, R.G. (1960). "Tuttle Creek Dam of Rolled Shale and Dredged Sand." J. Soil Mechanics and Foundation Division, ASCE, 86(SM6), . 1134. 